\title{
Development of RDE/ISC test methodology in light of Euro 6d/VI emissions limits
}

This paper discusses the fact that vehicle and powertrain test methods have long been guided by type approval requirements - with a focus ot the recent/current example of real driving emissions (RDE) and in-service conformity (ISC) test requirements. The implcations - current and future - of these testing requirement, which force the use of portable emissions measurement system (PEMS) are discussed. In this context, BOSMAL Automotive Research and Development Institute's PEMS systems are presented, and the systems' attributes and versatility are explored. Considerations for testing a very wide range of vehicle, engine and fuel types are mentioned. Non-legislative applications of PEMS systems are briefly explored; finally, it is shown that the emissions laboratory and its chassis dyno remain indispensable when conducting work on light duty exhaust emissions, even in the era of RDE.

Key words: RDE, Euro 6d, emission limits, high duty, PEMS

\section{EU real driving emissions (RDE) philosophy and introduction}

Legal requirements for the measurement and limitation of exhaust emissions have a long history in the EU, as well as in other markets, most notably the USA. Since the year 1990s, maximum permissible exhaust emissions of regulated pollutants in the EU have been updated several times (via the implementation of successive Euro standards), and the test procedure (laboratory test cycle) modified somewhat, but the fundamental means by which vehicles were tested remained unchanged, namely: laboratory tests performed under controlled conditions with the vehicle running on a chassis dyno. During this test, a well-defined and universally-known speed trace was followed by the vehicle and diluted exhaust emissions were measured, with a relatively simple calculation process determining the final results in terms of mass-per-distance (and particles-perdistance for particle number - PN). This approach guided the vast majority of research conducted on light duty vehicles destined for EU markets, as well R\&D carried out on their components, engine calibrations, aftertreatment systems, fuel, lubricants, etc. Over the last few years, a new chassis dyno driving cycle and slightly altered test procedure was introduced (the WLTP), but the fundamental approach did not change, as the driving cycle was welldefined and the vehicle was tested on a chassis dyno without the simulation of sloping terrain, variable traffic and weather conditions, etc. While the speed trace of the WLTP attempted to capture the complexity and variability of realworld driving, the speed trace for a given vehicle was the same for every test and defined in advance.

The use of such test procedures created strong pressure for manufacturers to produce vehicles, engines and engine calibrations which performed well under test conditions that is to say, the laboratory conditions (including the speed trace) known to be the official procedure at the time could be targeted in terms of optimization of exhaust emissions and limiting fuel consumption (which is strongly proportional to $\mathrm{CO}_{2}$ emissions). Such benefits were not always evident under driving conditions which differed from those occurring during official test procedures. Following a series of widely-reported and discussed concerns that real-world emissions (and fuel consumption) were much higher than during laboratory tests and that laboratory procedures represented something close to a best-case scenario, steps were taken to introduce a test procedure for measuring emissions (but not specifically fuel consumption) from light duty vehicles under normal conditions of use, i.e. when running on public roads. Such testing is possible thanks to PEMS (portable emissions measurement system), a measurement system which can be mounted on/in a vehicle and can travel around with it, measuring exhaust emissions and certain other parameters. The idea of PEMS testing and PEMS hardware itself is not new; it has a long history and was used on a smaller scale for many years by various parties in various contexts $[1,2]$. PEMS testing has been - and continues to be - carried out in multiple contexts, ranging from legally mandated official tests to $R \& D$ and fundamental emissions research (see, for example [2-6]).

In terms of the implementation of PEMS test as a legal test requirement for light duty vehicles, the situation changed dramatically real driving emissions (RDE) legislation was introduced in the EU [1,2], as part of updates to the Euro 6 regulation, in four packages:

- The first RDE package was adopted in May 2015 and defines the RDE test procedure, including the measurement of undiluted exhaust gas using PEMS apparatus and the calculation of emissions results.

- The second RDE package was adopted in October 2015 and defines the $\mathrm{NO}_{\mathrm{x}}$ Conformity Factors and their dates of entry into force.

- The third package was adopted in December 2016 and adds a Particle Number (PN) Conformity Factor (see Table 1) and inclusion of RDE cold-start emissions (which had previously been measured, but later excluded from the final results)

- The fourth package was adopted in May 2018 and introduces In-Service Conformity RDE testing and market surveillance and lowers the error margin of the 2020 $\mathrm{NO}_{\mathrm{x}}$ Conformity Factor from 0.5 to 0.43 (see Table 1). 
Table 1. Evolution of light-duty exhaust emissions limits in the EU

\begin{tabular}{|l|c|c|c|}
\hline & $\begin{array}{l}\mathrm{SI}-\mathrm{NO}_{\mathrm{x}} \\
{[\mathrm{mg} / \mathrm{km}]}\end{array}$ & $\begin{array}{c}\mathrm{CI}-\mathrm{NO}_{\mathrm{x}} \\
{[\mathrm{mg} / \mathrm{km}]}\end{array}$ & $\begin{array}{c}\text { All engines } \\
\text { with direct } \\
\text { injection - } \\
\mathrm{PN}[\# / \mathrm{km}]\end{array}$ \\
\hline $\begin{array}{l}\text { Euro 6 chassis dyno type- } \\
\text { approval limits } \\
\text { (NEDC/WLTP) }\end{array}$ & $\mathbf{6 0}$ & $\mathbf{8 0}$ & $\mathbf{6 . 0 \times \mathbf { 1 0 } ^ { \mathbf { 1 1 } }}$ \\
\hline $\begin{array}{l}\text { Euro 6 (2015) real-world } \\
\text { limits }\end{array}$ & 126 & 168 & - \\
\hline $\begin{array}{l}\text { Euro 6 (2016) real-world } \\
\text { limits }\end{array}$ & 126 & 168 & $9.0 \times 10^{11}$ \\
\hline $\begin{array}{l}\text { Euro 6 (2018) real-world } \\
\text { limits }\end{array}$ & 90 & 120 & $9.0 \times 10^{11}$ \\
\hline $\begin{array}{l}\text { Euro 6 (2020) real-world } \\
\text { limits }\end{array}$ & 85.8 & 114.4 & $9.0 \times 10^{11}$ \\
\hline
\end{tabular}

The differences in the 'chassis dyno' and 'real-word' limits in table 1 result from the use of conformity factors [1, 2]. Throughout the normal life of a vehicle, its emissions determined in accordance with the RDE requirements and emitted during any possible RDE test shall not be higher than the following not-to-exceed (NTE) values:

$$
\mathrm{NTE}_{\text {pollutant }}=\mathrm{CF}_{\text {pollutant }} \times \mathrm{TF}(\mathrm{p} 1, \ldots, \mathrm{pn}) \times \text { Euro-6. }
$$

As the transfer function (TF) is currently defined as taking a value of 1.0 and as the CF values defined in RDE legislation are all $>1$, this means that maximum permisaable emisions of certain compounds measured during an RDE test are be higher than emissions measured under laboraotry conditions on a chassis dyno. Self-evidently, the values of the legal CF factors - and any downwards revisions to those values - are of great concern to vehicle manufaturers and suppliers of components and systems related to emissions control, such as aftertreatment systems [1]. Even components and systems traditionally understood to have little in common with emissions and emissions control can have a part to play in meeting demanding NTE limits: for example, efforts to reduce vehicle mass (lightweighting) and improvements to aerodynamics (streamlining) can aid efforts to reduce regulated exhaust emissions under certain driving conditions. In the current climate of highly demanding exhaust emissions requirements (e.g. Euro 6d) and simultaneous demands to reduce fuel consumption and $\mathrm{CO}_{2}$ emissions [1, 2], even marginal benefits can add up to significant advantages in meeting goals and ensuring vehicles' legislative compliance in terms of exhaust emissions.

\section{EU real driving emissions (RDE) requirements in detail}

As mentioned previously, the core idea of PEMS testing is to drive a vehicle in a normal manner on public roads and measure the resulting emissions [1-11]. RDE testing is simply an extension of this idea, which criteria to determine whether the route and its sub-routes were normal and the maximum allowable emissions levels of certain regulated pollutants. The various pieces of RDE legislation ('RDE packages') mentioned in the previous section introduced and refined trip normality criteria, with the aim of ensuring that all RDE tests represented fair and reasonable use of a vehicle, based on time, distance, topography (altitude, gradient), speed, acceleration and measured $\mathrm{CO}_{2}$ emissions. These validity criteria were much debated and have been developed gradually, with the aim of facilitation quantitative determination of that tests conducted in an unrealistic manner. When identified as such, all the results from a nonnormal test are legally deemed non-valid, regardless of the magnitude of the emissions results. Some other, more general and more easily-met requirements apply: RDE trips have to last between 90 and 120 minutes; they have to include specified shares of urban, rural, and motorway driving, which must be conducted in precisely that order.

NTE emissions (resulting from the defined Conformity Factors) then apply to a range of ambient and driving conditions. For example, moderate ambient conditions are temperatures between 0 and $30^{\circ} \mathrm{C}$ and altitudes up to 700 $\mathrm{m}$; extended ambient conditions are temperatures between $1-7$ and $0^{\circ} \mathrm{C}$ and between 30 and $35^{\circ} \mathrm{C}$, and altitudes between 700 and $1300 \mathrm{~m}$. Regulated emissions emitted under the extended conditions mentioned above (whether altitude, temperature or both simultaneously) are divided by a fixed value of 1.6 to moderate the emissions results occurring under such conditions. When all calculation steps and corrections have been carried out, the final output emission value has to be below the NTE limit.

A Moving Average Window (MAW)-based methodology (EMROAD, originally developed by the Joint Research Centre - JRC - of the European Commission) is one of the main tools used to check the trip validity. In addition, for a PEMS trip to be valid, the driving cannot be either too aggressive nor too soft; this is checked via the calculation of the 95th percentile of the vehicle speed-positive acceleration product and via the relative positive acceleration value, both assesses for the urban, rural, and motorway phases individually. Another assessment criterion is the positive altitude gain during the PEMS trip, which is limited to $1200 \mathrm{~m} / 100 \mathrm{~km}$, mathematically equivalent to a constant slope of 0.012 radians.

Once the trip validity has been confirmed, PEMS data are post-processed, with a series of correction factors applied to normalize the results. The most important normalization step balances the raw regulated emissions against $\mathrm{CO}_{2}$ (compared to emissions of $\mathrm{CO}_{2}$ from the same vehicle undergoing a WLTP test); this way, demanding trips which caused higher emissions (regulated and $\mathrm{CO}_{2}$ ) can be considered valid, with the results reduced somewhat by the aforementioned correction. As $\mathrm{CO}_{2}$ is strongly proportional to the energy supplied by the combustion engine over a given driving cycle, a specific evaluation factor is used in the case of plug-in hybrid vehicles, which compares $\mathrm{CO}_{2}$ emissions during the RDE test and $\mathrm{CO}_{2}$ emitted over the WLTP test in Charge Sustaining mode. Ongoing powertrain electrification (hybridization) in the automotive industry will continue to evolve and may create further challenges for RDE legislation to adapt to. Apart from hybridization, the use of alternative engine concepts and even exotic solutions such as the use of dual fuel systems may become more widespread in the future. Thus, despite already having been updated many times, the RDE data evaluation methodology will continue to be reviewed against technological progress and will almost certainly be subject to future updates $[1,2]$. 


\section{Other types of legislative testing using PEMS equipment}

While it is not the main focus of this paper, legislation on emissions from heavy duty engine engines in fact has a longer history than RDE testing for light duty vehicles. Following similar trends in the USA [1], since 2011 the EU has required in-service conformity (ISC) testing of various types of heavy duty engines. Such testing is carried out by testing a heavy duty vehicle equipped with the concerned engine - for example, a truck or bus. Non-road mobile machinery (NRMM) is now also subject to similar requirements. NRMM is a broad category, containing machinery with very different characteristics, equipped with combustion engines of varying size. In the case of NRMM, there are considerable differences from road vehicles, due to the fact that such machines' primary function is to carry out work (such as excavation or lifting), instead of covering distances of up to several hundred $\mathrm{km}$ during a single period of engine operation. Differences in testing details and practicalities are significant, yet nevertheless, the physical basis of ISC testing for heavy duty and NRMM applications has many similarities with RDE testing in terms of its usage of PEMS to sample exhaust gas and limits set by means of the CF mechanism. As will be shown later in this paper, the emissions measurements and result calculation processes are sufficiently similar that in many cases a single PEMS system can be used on a range of vehicles, to perform either RDE or ISC (HD/NRMM) testing.

\section{BOSMAL's PEMS hardware and computer software for RDE/ISC testing}

Various manufacturers have produced emissions testing equipment and computer software capable of conducted PEMS testing in full accordance with EU RDE and ISC requirements, and often also following US specifications for HDUIT equipment. BOSMAL Automotive Research and Development Institute Ltd possesses two systems which fully meet all RDE/ISC requirements, making them suitable for testing light and heavy duty vehicles, as well as NRMM, in line with all applicable EU legislation. The first system, by AVL was manufactured and commissioned in 2016 (Fig. 1 and Fig. 2). A system from Horiba was manufactured and commissioned in 2018 (Fig. 3 and Fig. 4).

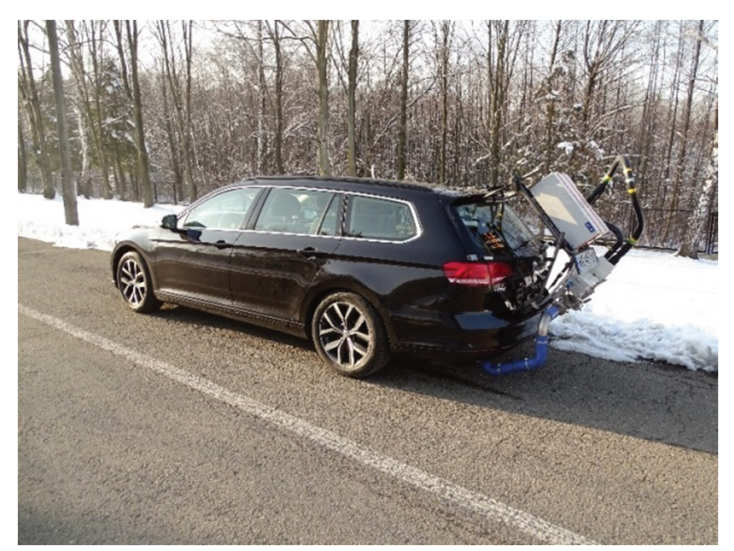

Fig. 1. AVL PEMS system installed on a passenger car. The gas PEMS unit is not visible as it is located inside the vehicle cabin. The PN PEMS, the exhaust flow meter, the sampling line and tubing for re-routing the exhaust are all visible at the rear

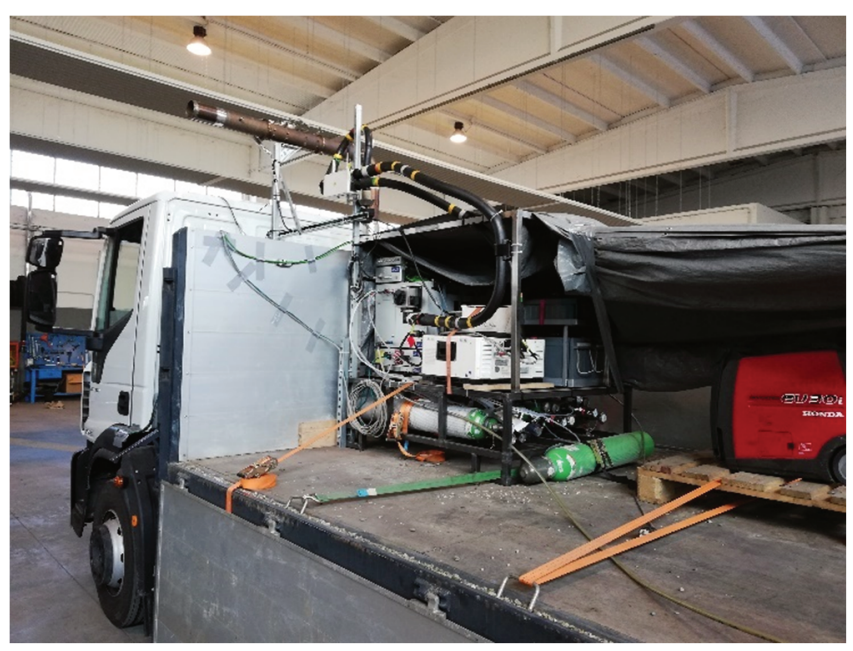

Fig. 2. AVL PEMS system installed on the load carrying area of a heavy duty vehicle

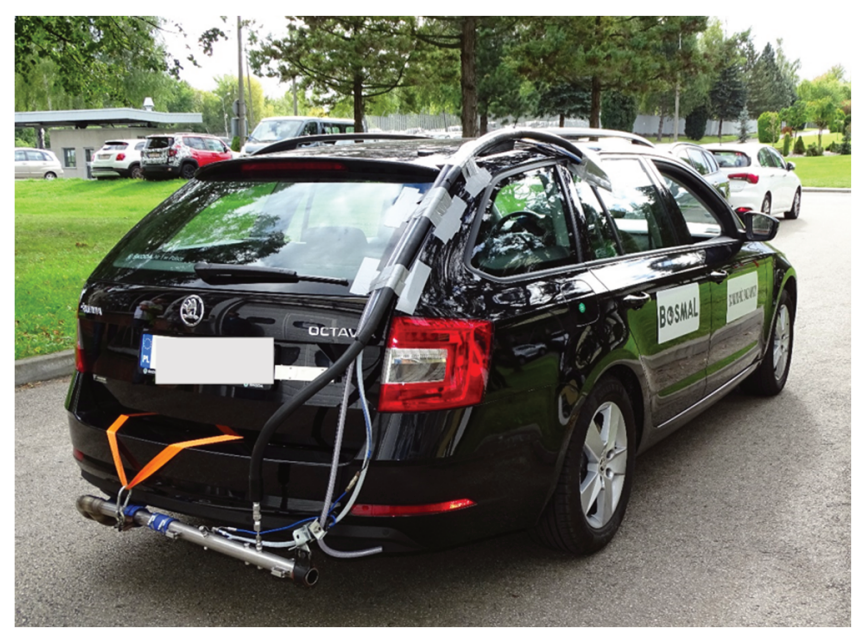

Fig. 3. Horiba PEMS system installed in a passenger car

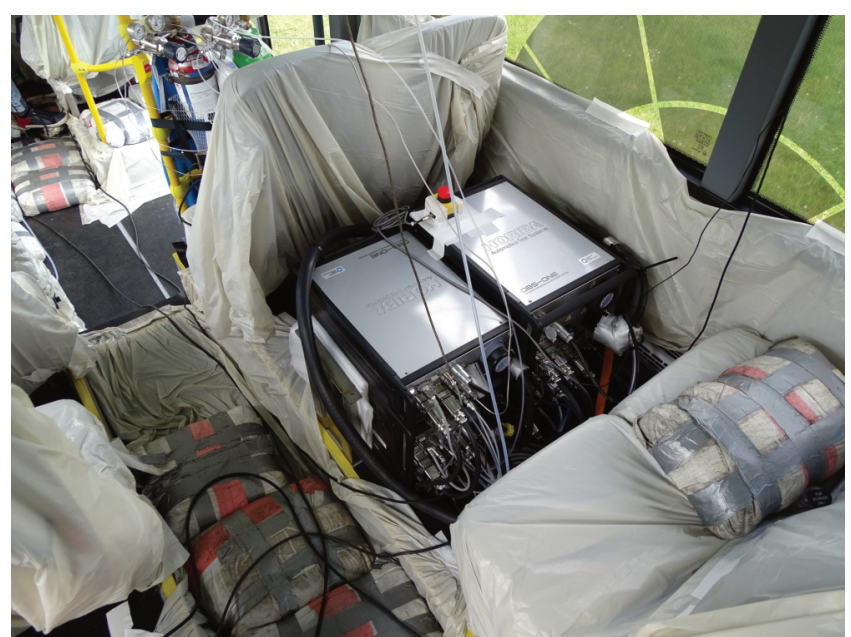

Fig. 4. Horiba PEMS system installed in the passenger seating area of an urban bus. (Note the presence of sandbags serving as ballast surrounding the equipment)

Both systems are equipped with high capacity batteries suitable for powering the equipment, including laptop computer. The capacity of the two systems' batteries is such that an RDE test can easily be performed on battery power. 
For HD/NRMM ISC testing, which is longer in duration, both systems can be powered by a portable generator (visible on the right side of Fig. 2).

Both the aforementioned PEMS systems' hardware and software is specifically designed to quantify emissions of regulated gaseous and solid pollutants from vehicles powered by internal combustion engines in full accordance with all relevant requirements formalized in Commission Regulation (EU) No. 2017/1151 with all relevant amendments, as well as applicable legislation for in-service conformity (ISC) testing of heavy duty vehicles (Commission Regulation (EU) No. 2009/595, with multiple updates) and NRMM.

As required by the aforementioned legislation, both systems measure concentrations of $\mathrm{CO}, \mathrm{NO}, \mathrm{NO}_{2}\left(\right.$ or $\left.\mathrm{NO}_{\mathrm{x}}\right)$ and $\mathrm{CO}_{2}$. While there are some small differences in the two systems' analyzers, in both cases measurement of the aforementioned gaseous species is in full accordance with all applicable legislation. Both systems are also capable of measuring THC - measurement of this compound is not required for RDE testing, but is required for heavy duty ISC testing. In both systems, the measured concentrations are converted into mass emissions vectors using the information from the measured exhaust flow. Both concentration and mass-based results are available following export of the test results, at 1 or $10 \mathrm{~Hz}$.

Following the introduction of $\mathrm{PN}$ measurement requirements for both RDE and ISC testing (and upcoming requirements for NRMM), both systems feature their own PN counting module. These two PN modules have different particulate quantification methods (diffusion charger in the case of the AVL system versus condensation particle counter in the Horiba system), but are both in full accordance with all applicable RDE and ISC requirements. $\mathrm{PN}$ is counted with a nominal lower cut-off point of $23 \mathrm{~nm}$ (the same as for laboratory chassis dyno measurements), with the sample pre-treatment system ensuring that only solid (and not volatile) particles are counted. Both PN modules function as an integrated component of their respective parent systems, but can also be deactivated and even physically removed from the system when not required - thereby reducing system volume, weight and power consumption.

In addition to the aforementioned emissions measurement hardware, each system also features a controlling computer for control of the system and archiving of results during testing. Additionally, both systems are equipped with software for pre- and post-processing of results, data export, as well as various means of data visualization (including map-based presentation of results) and preparation of reports in the rigid format required for submission to type approval authorities (e.g. EMROAD).

Depending on the precise configuration, the weight of each system and all its accessories, batteries, etc. is analogous to the weight of 1-2 adult humans - i.e. a very normal load for even a small passenger car, or negligible load for a heavy duty vehicle. (In the case of NRMM not designed to carry load on the chassis, the weight of the PEMS is normally rather insignificant compared to the weight of the machinery itself.)
As required by all PEMS-based legislation, exhaust gas is sampled raw from a sampling probe connected to the tailpipe of the vehicle or piece of machinery. A heated sampling line is used to transfer the exhaust gas to the PEMS itself. Both BOSMAL's systems can use one of two sampling lines according to the characteristics of the vehicle under test. Where possible, the shorter line is used, for both systems. All sampling lines feature heating circuits with temperature regulation. For legislative testing, the temperature of the sampling line is set to $191^{\circ} \mathrm{C}$. The heated line minimizes condensation and related sample loss and the sample line leading to the gas analyzers includes a disposable filter to prevent fouling of the analyzers with particulate.

In addition to high-quality chemical analyzers, a key requirement of all PEMS-based legislation is accurate determination of the exhaust mass flow rate. In line with the legislation, this can be achieved in several ways, but the preferred method is direct measurement via a flowmeter through which the entire exhaust gas flow passes. This direct measurement does not depend on data obtain from the engine's ECU via the OBD port (though it can be crosscorrelated with such data) and provides a truly independent measurement. Depending on the vehicle or piece of machinery under test and the type and size of the engine used to power it, the magnitude of this mass flow can vary greatly. In light of this, both BOSMAL's systems feature a range of exhaust flow meters with tubing of different diameters, meeting all the applicable demands of applicable legislation, all of which measure the exhaust flow via the Pitot method. The measurement range depends on the tube connected to the flow meter, with both systems possessing sufficient flow meters and tubes to cover all passenger cars, as well as vans, HD vehicles (including large buses and coaches) and many types of NRMM. Testing of more exotic vehicles and machines, including military vehicles, ships, trains, generators and even aircraft is also possible, as long as physical restrictions regarding the use of the exhaust gas mass flow meter can be overcome. (For certain types of machinery and non-road vehicles, use of the exhaust gas mass flow meter may be impractical or unsafe - in such cases, the flow of exhaust gas reported by the ECU can be used.)

All PEMS systems must feature a weather station measuring ambient temperature and humidity and a GPS receiver - in the case of BOSMAL's systems, all sensors and the GPS units fulfil all relevant requirements the applicable legislation. While ambient temperature, humidity and pressure are monitored and reported (results for the entire test and at $1 \mathrm{~Hz}), \mathrm{NO}_{\mathrm{x}}$ results are not corrected for ambient humidity by default, in line with legislation (although this option is available and can be used on request).

Since PEMS testing contains a number of steps to be performed on a range of analyzers, an automated control system is required, since human triggering of purging, calibration, data storage (etc.) would be too arduous and errorprone. Thus, a specially-designed automation and acquisition system is a key component of any PEMS.

Both systems' control software includes functions for tasks such as purging and leak checking, which are execut- 
ed prior to every test. Similarly, according to BOSMAL procedures, the legislative requirement for analyzer calibration before and after the test is carried out. Zeroing of the exhaust mass flow meter is also carried out before every test. The PN system is leak checked and zeroed before every test. The results of these calibrations are stored and exported as an integral part of the test report, for analysis when reviewing test results. As per the manufacturer's recommendations, at least once every 12 months both units are returned to their respective manufacturer's service department for maintenance - these maintenance procedures are not explicitly mandated by legislation, but ensure sound emissions testing practice in terms of checks of the functioning of heaters, coolers, pumps, fans, transformers, etc. In line with legislative requirements, the linearity of both systems' gaseous analyzers is checked (and if necessary corrected) at least once every three months; the linearity of the both systems' exhaust flow meters and other sensors is checked at least once a year. All calibration gases used are of high quality and meet or exceed all applicable legislative demands. As with chassis dyno CVS-bag testing, the expiry dates of the calibration gases used are stored in a database and hard copies as well as scans of all calibration gas certificates are kept.

Both PEMS systems' control software - and in particular the post-processing functionality - is subject to regular updates by the system manufacturer (note that each RDE package has introduced multiple significant changes requiring modifications to the post-processing, emissions calculation and trip validity determination criteria).

The sine qua non of a successful RDE test can be defined as the PEMS equipment (namely its installation, preparation and calibration) and the suitability of test route. The former aspect has been described previously; the latter aspect is expanded upon here, based on the example of one of BOSMAL's RDE-compliant routes in southern Poland. (Note that in discussions of this nature, a "successful" RDE test is not necessarily one where $\mathrm{CF}$ values for regulated pollutants are below legal limits; a "successful" RDE test is one which satisfies all applicable RDE requirements, regardless of the emissions results obtained from that test.)

BOSMAL has a range of routes route specially developed with the full requirements of Commission Regulation (EU) No. 2017/1151 in mind are proposed for RDE tests, as well as routes for various types of HD vehicles. These routes have been successfully executed on a range of LD vehicles. In accordance with the demands of Commission Regulation (EU) No. 2017/1151, all routes consist of three sub-routes (called urban, rural and motorway).

For non-legislative testing and R\&D purposes, portions of the routes as defined above can be omitted, repeated or performed in a different order, giving many possible combinations to investigate emissions from alternative driving scenarios (examples: cold start followed by motorway operation; urban-only routes). Nearby mountains also provide for multiple possibilities for more demanding driving routes over mountainous terrain at altitudes exceeding $700 \mathrm{~m}$.

Some details and commentary on the sub-routes of the sample route is presented in the remainder of this section.
The urban, rural and motorway sub-routes have been designed with the demands of Commission Regulation (EU) No. 2017/1151 and also with the practicalities of RDE-PEMS testing in mind. Each sub-route covers $>25$ $\mathrm{km}$, such that the total distance covered by the three combined is approximately $85 \mathrm{~km}$. Indicative approximate distance shares are: urban $-40 \%$, rural $-30 \%$, motorway $30 \%$. Continuity of the complete trip (urban-rural-highway) is assured by the fact that the end point of one section is the start point of the following section; the transitions from one section to another are seamless and do not require any unnatural or artificial driving maneuvers.

The urban sub-route is a near-loop (the start and end points are less than 500 metres apart). The urban route's speed profile varies with the traffic conditions (time of day, day of week). The legal speed limits encountered on the urban route is are in the range $40-70 \mathrm{~km} / \mathrm{h}$; for the vast majority of the route the legal speed limit is $50 \mathrm{~km} / \mathrm{h}$. The urban route features multiple sections where heavy traffic is common, junctions controlled by traffic lights, etc. but is typically not characterised by completely gridlocked traffic, such that the mean speed is typically safely within the 15$40 \mathrm{~km} / \mathrm{h}$ range and stop events account for $6-30 \%$ of the urban travel time. The urban route leads directly into the rural route.

The rural sub-route is a return journey (outwards leg/return leg). The rural route features driving on a dual carriageway with speed limits ranging from $50-100 \mathrm{~km} / \mathrm{h}$ and including multiple sets of traffic lights, such that a minimum of at least one stop event typically occurs on this sub-route. A controlled U-turn manoeuvre at a junction is used to change the driving direction at the end of the outwards leg. When the return leg is complete, this route leads directly into the motorway route.

The motorway sub-route is a return journey (outwards leg/return leg) this sub-route consists almost entirely of driving on a dual carriageway where the speed limit is 120 $\mathrm{km} / \mathrm{h}$ and congestion is rare, such that well over 5 minutes' driving occurs at speeds $>100 \mathrm{~km} / \mathrm{h}$, as required for a valid RDE trip. However, the route features an "interruption", where vehicle speed is reduced: there is an acute curve in the motorway route where the legal speed limit is progressively reduced from $120 \mathrm{~km} / \mathrm{h}$ to $60 \mathrm{~km} / \mathrm{h}$, returning to 120 $\mathrm{km} / \mathrm{h}$ immediately after the curve (this situation is the same when travelling in both directions). Including such a feature in the route ensures that speeds in the range 90-110 km/h are always included in the motorway sub-route, since safe and legal negotiation of this curve requires speeds considerably lower than the general speed limit of $120 \mathrm{~km} / \mathrm{h}$. In this way, the driver needs to be given no special instructions to drive significantly slower than the speed limit when driving the motorway sub-route. The end of the outwards leg coincides with a junction, where an exit ramp and a roundabout are used to enter the carriageway travelling in the opposite direction. This roundabout-facilitated U-turn manoeuvre requires significantly lower speeds (applicable to rural and urban driving), but is typically achievable without stopping the vehicle. The return leg of the motorway sub-route ends at a junction within $1 \mathrm{~km}$ of the start 
point of the urban sub-route, such that the entire urbanrural-motorway route is very nearly a closed loop.

Using a route which is a loop or near-loop has evident advantages in terms of reducing travelling time back to base following a test. For RDE testing including the cold start event (according to RDE packages 3 and above), route planning is imperative, because once started, the cold start and warmup cannot be paused or repeated - RDE requirements state that the vehicle must be parked for between 6 and 56 hours before the cold start and start of driving. Following engine startup (cranking) for the cold state, the vehicle must begin to move before 15 seconds elapse (i.e. extended initial idling, even if forced by the prevailing traffic conditions, immediately invalidates a test). There are also additional requirements concerning driving during the cold start period (defined as the coolant reaching a temperate of $70^{\circ} \mathrm{C}$ for the first time, or 300 seconds elapsing, whichever occurs first). In light of these multiple requirements, which often difficult to fulfil simultaneously, and the strongly anisotropic nature of emissions behaviour following a cold start, route planning for RDE testing according to the 3rd and 4th packages is even more complex than for earlier eras of RDE testing where cold start data was explicitly excluded from the final emissions results.

A further factor which must be considered is terrain: the altitude profile of BOSMAL's RDE route covers frequent yet gentle undulations in the terrain, without large hills. The altitudes of the start and end points differ by $<20$ metres (RDE legislation requires $<100 \mathrm{~m}$ difference between these points). The mean altitude of the entire route is approximately 350 metres above sea level. When the entire urbanrural-motorway route is performed, the cumulative distance-specific altitude gain is typically approximately $850 \mathrm{~m} /$ $100 \mathrm{~km}$ and is always $<1000 \mathrm{~m} / 100 \mathrm{~km}$. The highest altitudes reached by the vehicle over the full route are all $<430$ metres above sea level, thus meaning that no portion of the standard route lies in the altitude range which counts as extended conditions.

Many other RDE routes close to BOSMAL's headquarters in Bielsko-Biala have been defined and validated, for example a route which includes higher altitudes (rural subroute including altitudes $>700 \mathrm{~m}$ ) to create a route where a significant portion of the driving occurs in the RDE extended category. BOSMAL also has other RDE-complaint test routes at various locations, including in EU countries other than Poland. Some routes are in southern Europe, meaning the temperature in the winter is significantly higher than in Poland and snowfall is rare.

A variety of variants and changes to the legislative procedure can be made to investigate the impact on the results and thus gain an insight into real-world emissions in scenarios outside RDE boundary conditions. Such modifications can include:

- testing using altered $\mathrm{CO}_{2}$ input values;

- testing varying the order of the three sub-routes - for example: [cold start]-motorway-rural-urban; [cold start] -rural-motorway-urban;

- testing using an urban traffic jam route with very low mean speed and periods of vehicle standstill (stop time) significantly exceeding the RDE limit for that parameter $(30 \%)$;

- testing using modified sub-route distance shares - examples: urban $70 \%$, rural $15 \%$, motorway $15 \%$; urban $10 \%$, rural $0 \%$, motorway $90 \%$;

- testing at ambient temperatures below the RDE extended range (i.e. down to the lower limit of the equipment: $\left.-10^{\circ} \mathrm{C}\right)$ :

- post-processing of results to include emissions at idling and speeds $<1 \mathrm{~km} / \mathrm{h}$;

- tests performed with heavy electrical load during driving (e.g. high ambient temperature, max. air conditioning power or low ambient temperature, heated seats, cabin heater and all lights on) for assessment of the impact on the emissions (both regulated and $\mathrm{CO}_{2}$ ).

Such deviations from the legislative RDE procedure are emphatically not to be employed during legislative RDE tests, but can form an important part of non-legislative, RDE-like PEMS test procedures, with the aim of gaining a deeper understanding of emissions behaviour from vehicles under demanding (yet still realistic) operating conditions outside RDE boundaries. Such insights can be used to provide mathematical input data for real-world emissions inventories and can also assist with efforts to make powertrains, calibrations and aftertreatment systems as futureproof as possible, by testing them under conditions exceeding current type approval requirements.

As a result of favorable assessments of the compliance of its PEMS hardware and software with all applicable requirements, BOSMAL is an accredited laboratory for conducting RDE-PEMS and ISC-PEMS (HD, NRMM) tests in line with all relevant EU legislation (accreditation No. AB 128 according to PN-EN ISO/IEC 17025:2005 available here:

https://www.bosmal.eu/userfiles/file/Certyfikaty/Accreditat ion_issue_No_17_02_08_2018-EN.pdf).

\section{The laboratory (chassis dyno) environment in the era of RDE}

The publication of RDE requirements in the EU represented a revolution in the automotive industry, in contrast to decades of evolution $[1,16]$. It is clear that RDE requirements will remain in force in the EU and will become more stringent. A number of other parties and legal jurisdictions are either implementing similar requirements, or will do in the coming years - the global "market" for RDE development will increase further beyond its current level. A process has even begun to harmonize RDE testing internationally $[17,18]$, though regional emissions limit values will differ somewhat. While RDE requirements are by far the most challenging emissions requirements for the EU market (and other markets with current or planned RDE legislation - i.e. various Asian counties; potentially others), laboratory chassis dyno testing remains a very important element. RDE tests occurring under real-world operating conditions have a very wide range of acceptable parameters and are at the mercy of the prevailing traffic and weather conditions occurring during the test. This leads to RDE and PEMS testing in general being very realistic, but also characterized by low repeatability. For the reason of repeatability, among others, the chassis dyno remains an indispensa- 
ble environment for emissions development work at the Euro $6 \mathrm{~d} / \mathrm{RDE}$ level. Use of a chassis dyno in this context includes, but is not limited to, the following activity types:

- verification of the PEMS system installation before (and/or after) an RDE test, as required by RDE legislation (see [15] for a recent detailed discussion);

- determination of WLTP $\mathrm{CO}_{2}$ emissions values in cases where this information is not available from another reputable source (required for post-processing of RDE results);

- for execution of vehicle preconditioning cycles prior to RDE tests (as an alternative to performing such activities on public roads);

- and - most importantly - for simulation of RDE tests, routes, segments and scenarios and reproduction of given driving conditions on demand.

Concerning the first point in the list above, the aforementioned chassis dyno verification procedure, during which results from the PEMS (including distance travelled) are compared with results from the laboratory is always performed for each individual installation on light duty vehicles. (HD vehicles and NRMM are not testable on a chassis dyno and are subject to their own verification procedures, not discussed here.) BOSMAL's emissions laboratories' systems (including the chassis dynos) are maintained, checked and calibrated according to procedures which meet the applicable demands of legislation including UNECE Regulation No. 83, UNECE GTR No. 15 and Commission Regulation (EU) No. 2017/1151.

Concerning the last point in the list above (simulation of RDE conditions on the chassis dyno - see Fig. 5), there are several important aspects worth mentioning. Firstly, the creation of a pre-programmed speed trace, together with the display of customized gearshifts is easily implemented in a modern chassis dyno emissions laboratory (such as those at BOSMAL). This allows virtually any recorded speed trace and gearshift pattern to be programmed as a test cycle. The speed trace and gearshifts could come from virtually an source - as examples, from a previous RDE test, from recorded real-world vehicle usage, from a simulation study, or from creation a scenario suspected to be challenging in terms of emissions control. Secondly, modern chassis dynos are capable of simulating inclines (slopes) during vehicle running, via mathematical modification of simulated running resistance [13]. In BOSMAL's exhaust emissions laboratories, a slope profile can be loaded alongside speed and gearshift profiles to create a reproduction of the load experienced by the powertrain while driving a given route. Finally, ambient conditions have a considerable impact on exhaust emissions, fuel consumption - and even drivability, $\mathrm{NVH}$, etc. - and so chassis dyno test facilities with climate control (such as BOSMAL's facilities) possess a distinct advantage in terms of full replication of test conditions for chassis dyno RDE simulation. The economic and logistical advantages of the ability to change temperature on demand (rather than waiting for the desired weather conditions to occur) are self-evident.

The legislative method for laboratory measurement of exhaust emissions from light duty vehicles running on chassis dynos (often called the CVS-bag method) is gener- ally of limited use for extended test cycles, due to the finite number and capacity of the sample bags. Furthermore, the CVS-bag measurement gives results of high accuracy, but extremely low resolution: one result per phase (i.e. per sample bag). Thus, a phase (bag-sampling event) lasting say 20 minutes would give one measurement per $1200 \mathrm{sec}$, i.e. a measurement frequency of $\sim 0.0008 \mathrm{~Hz}$. Non-legislative equipment used for continuous ('modal') analysis of undiluted or diluted exhaust can be used to provide emissions measurement at much higher resolution - up to $10 \mathrm{~Hz}$ (see [12-14] for detailed descriptions of BOSMAL's hardware of this type). However, PEMS analyzers themselves can also be used on the chassis dyno, or a combination of laboratory modal analyzers and PEMS can be used (Fig. 5), thereby adding to the breadth and robustness of the emissions results. Such a setup could apply both systems in parallel, to perform two sets of measurements from the same sample point (e.g. the tailpipe), or the different systems could be connected to different sampling points along the powertrain, to assess the effectiveness of various aftertreatment system components (see [13] for a discussion of this technique). Pollutants and compounds of interest not currently measured by standard PEMS equipment (such as $\mathrm{NH}_{3}, \mathrm{~N}_{2} \mathrm{O}$ and particle size distribution) can be measured in this way, by means of laboratory equipment.

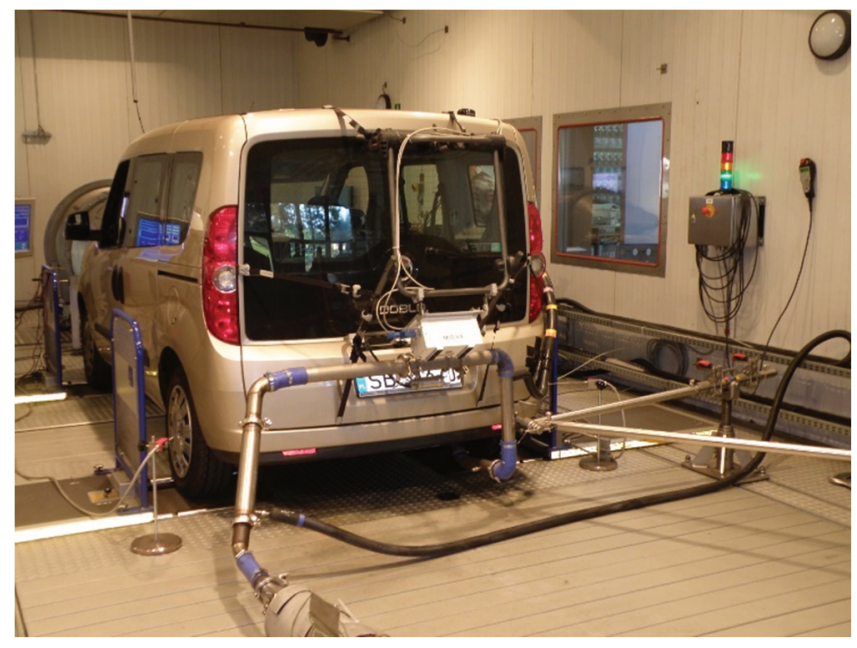

Fig. 5. PEMS system installed on a light duty vehicle undergoing an RDE simulation test on the chassis dyno.

It is also important to note that RDE NTE limits apply to emissions from a vehicle quantified using PEMS equipment (and not laboratory equipment) and calculated using the RDE post-processing procedure. For that reason, using PEMS equipment for RDE-based research has certain advantages in terms of the comparability of the measurement with a genuine RDE test outside the laboratory. While the correlation in emissions results generated by modern, wellmaintained and prepared, RDE-compliant legislative PEMS equipment and legislative laboratory CVS-based equipment is generally very good (see [15] for a recent assessment and discussion), certain identifiable differences in results remain. The accuracy requirement of the PN module is the least stringent $( \pm 50 \%$ of laboratory reference value) [15]. PEMS results which give unexpectedly high emissions (i.e. exceeding, or very close to, the legislative limit) should be 
further investigated on the chassis dyno, performing modal emissions measurements in parallel. On the other hand, PEMS equipment is expensive, rather time-consuming to set up and in the current legislative environment, demand for such equipment is very high - and so the use of PEMS for testing on the chassis dyno must be justified, as not every case warrants the use of portable equipment in a stationary (laboratory) environment. In situations where its use is not found to be justified, laboratory equipment for modal analysis is an eminent alternative for use during RDE simulation testing. Some types of somewhat smaller and simpler PEMS equipment exist, often known as SEMS (Smart Emissions Measurement System). Such systems do not fulfill all RDE or ISC requirements, but can be used for $\mathrm{R} \& \mathrm{D}$ purposes, including in the chassis dyno environment, sometimes combined with the laboratory equipment for modal measurement to provide a comprehensive, costeffective chassis dyno-based emissions measurement approach.

\section{Conclusions}

The introduction of ISC and RDE requirements in the EU (and, progressively, the introduction of similar requirements in other jurisdictions) is a radical departure from requirements for emissions measurement and control in previous eras. Rugged, flexible PEMS equipment is required to perform the required legislative and $R \& D$ testing on the very wide range of vehicles and pieces of machinery subject to this legislation. RDE testing of passenger cars is now the most demanding requirement in terms of emissions control, and this forces the need for very high numbers of tests for development and calibration purposes. However, because of the nature of the open road (real world) and the chassis dyno (controlled laboratory environment), the chas- sis-dyno based emissions laboratory is in fact more relevant than ever, despite the real world ethos of RDE. As this paper has discussed, equipment of the type BOSMAL has at its disposal (multiple PEMS suitable for light duty vehicles (and HD/NRMM), climate-controlled chassis dyno facilities) are an absolute necessity in the era of RDE. . In addition to BOSMAL fulfilling all legislative RDE/ISC requirements - a fact attested to by the company offering accredited services (Fig. 6) - R\&D services relating to $\mathrm{RDE} / \mathrm{ISC}$ requirements are also provided. The symbiotic advantages provided by the chassis dyno/PEMS/modal analysis combination allows BOSMAL to provide the full range of services relating to the latest emissions type approval requirements for light duty vehicles.

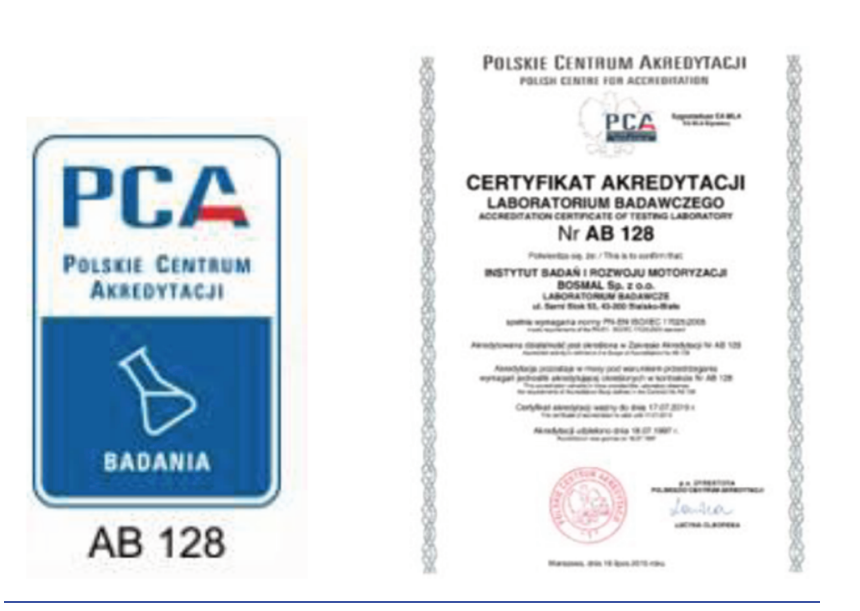

Fig. 6. BOSMAL's accreditation certificate for testing laboratory AB 128 with confirmation of the PN-EN ISO/IEC 17025:2005 standard. The range of accreditation include RDE testing and ISC testing for HD and NRMM

\section{Nomenclature}

$\mathrm{CO}$

$\mathrm{CI}$ compression ignition

FC fuel consumption

ISC in-service conformity

$\mathrm{N}_{2} \mathrm{O}$ nitrous oxide

$\mathrm{NH}_{3}$ ammonia

NO nitrogen oxide

$\begin{array}{ll}\mathrm{NO}_{2} & \text { nitrogen dioxide } \\ \mathrm{NO}_{\mathrm{x}} & \text { oxides of nitrogen } \\ \text { PEMS } & \text { portable emsisions measurement system } \\ \mathrm{RDE} & \text { real driving emissions } \\ \text { SEMS } & \text { Smart Emissions Measurement System } \\ \text { THC } & \text { total hydrocarbons } \\ \text { WLTP } & \text { Worldwide Harmonised Light Vehicle Test Proce- } \\ & \text { dure }\end{array}$

\section{Bibliography}

[1] BIELACZYC, P., WOODBURN, J. Trends in automotive emission legislation: impact on LD engine development, fuels, lubricants and test methods: a global view, with a focus on WLTP and RDE regulations. Emissions Control Science Technology. 2019, 5(1), 86-98. DOI: 10.1007/s40825019-0112-3

[2] BIELACZYC, P., WOODBURN, J. Trends in automotive emissions legislation: impact on LD engine development, fuels and lubricants, and test methods - a global view with a focus on WLTP and RDE regulations - Summary of the 6th International Exhaust Emissions Symposium (IEES), Combustion Engines. 2018, 174(3), 56-65. DOI: 10.19206/ CE-2018-306
[3] Bielaczyc, P. WLTP, RDE and $\mathrm{CO}_{2}$ legislation: a global view and their impacts on engine technologies and testing procedure. 2nd Annual Real Driving Emissions Forum. 6th7th March 2018, Amsterdam.

[4] BIELACZYC, P. Global development of emissions reduction strategies from light duty vehicles. 2nd International Conference on the Sustainable Energy and Environmental Development. IOP Conf. Series: Earth and Environmental Science. 2019, 214, 012139. DOI: 10.1088/1755-1315/214/ $1 / 012139$

[5] BIELACZYC, P. WLTP, RDE and global emissions regulations: Current and future development in Europe and worldwide. 6th International Conference Real Driving Emissions. 17-18 October 2018, Berlin. 
[6] BIELACZYC, P. O badaniach emisji związków szkodliwych spalin $\mathrm{z}$ silników samochodowych $\mathrm{w}$ warunkach trakcyjnych metodą RDE (PEMS). Przegląd Techniczny. 2016, 24, 56-57.

[7] MERKISZ, J., FUC, P., LIJEWSKI, P., BIELACZYC, P. The comparison of the emissions from light duty vehicle in on-road and NEDC test. SAE Technical Paper 2010-011298, 2010. DOI: 10.4271/2010-01-1298

[8] MERKISZ, J., PIELECHA, J., BIELACZYC, P., WOODBURN, J. Analysis of emission factors in RDE tests as well as in NEDC and WLTC chassis dynamometer tests. SAE Technical Paper 2016-01-0980, 2016. DOI:10.4271/201601-0980

[9] MERKISZ, J., BIELACZYC, P., PIELECHA, J., WOODBURN, J. RDE testing of passenger cars: the effect of the cold start on the emissions results. SAE Technical Paper 2019-01-0747, 2019. DOI:10.4271/2019-01-0747

[10] BIELACZYC, P., MERKISZ, J., PIELECHA, J., WOODBURN, J. A comparison of gaseous emissions from a hybrid vehicle and a non-hybrid vehicle under real driving conditions. SAE Technical Paper 2018-01-1272, 2018, DOI: 10.4271/2018-01-1272

[11] PIELECHA, J. MERKISZ, J., BIELACZYC, P., WOODBURN, J. Gaseous emissions from a hybrid vehicle and a non-hybrid vehicle measured under real driving conditions via PEMS. FISITA Technical Paper F2018/F2018-PTE-266.

[12] BIELACZYC, P., SZCZOTKA, A., WOODBURN, J. Development of vehicle exhaust emission testing methods -

\begin{abstract}
Piotr Pajdowski, DEng. - Engine Research Department, BOSMAL Automotive Research \& Development Institute Ltd in Bielsko-Biała.

e-mail: piotr.pajdowski@bosmal.com.pl
\end{abstract}

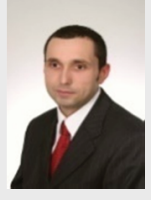

Joseph Woodburn, MSci - Engine Research Department, BOSMAL Automotive Research \& Development Institute Ltd in Bielsko-Biała.

e-mail: joseph.woodburn@bosmal.com.pl
BOSMAL's new emission testing laboratory. Combustion Engines. 2011, 144, 3-12.

[13] BIELACZYC, P., PAJDOWSKI, P., SZCZOTKA, A., WOODBURN, J. Development of automotive emissions testing equipment and test methods in response to legislative, technical and commercial requirements. Combustion Engines. 2013, 1, 28-41.

[14] BIELACZYC, P., KLIMKIEWICZ, D., WOODBURN, J., SZCZOTKA, A. Exhaust emission testing methods BOSMAL's legislative and development emission testing laboratories. Combustion Engines. 2019, 178(3), 87-97. DOI: 10.19206/CE-2019-316

[15] VARELLA, R.A., GIECHASKIEL, B., SOUSA, L., DUARTE, G. Comparison of portable emissions measurement systems (PEMS) with laboratory grade equipment. Appl. Sci. 2018, 8, 1633. DOI: 10.3390/app8091633

[16] ENGELJEHRINGER, K. Emission regulation and development - from evolution to a paradigm shift (PTNSS-2017D17). VII International Congress on Combustion Engines PTNSS, Poznan, 27th-29th June 2017.

[17] Informal document GRPE-77-30, The need for an RDE GTR, 77th GRPE, 6-8 June 2018, https://www.unece.org/ fileadmin/DAM/trans/doc/2018/wp29grpe/GRPE-77-30e__RDE_at_June_2018_GRPE_session_vs4.pdf

[18] Informal document WP.29-175-32. Request for the authorization to develop a new UN GTR on Global Real Driving Emissions, 175th WP.29, 19-22 June 2018, https://www.unece. org/fileadmin/DAM/trans/doc/2018/wp29/WP29-175-32e.pdf

Piotr Bielaczyc, DEng. - Head of the Engine Research Department at the BOSMAL Automotive Research \& Development Institute Ltd in BielskoBiała.

e-mail:piotr.bielaczyc@bosmal.com.pl

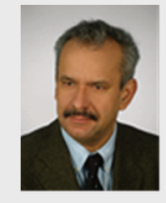

Bartosz Puchałka, MEng. - Engine Research Department, BOSMAL Automotive Research \& Development Institute Ltd in Bielsko-Biała.

e-mail: bartosz.puchalka@bosmal.com.pl 